\title{
Destino de Prazer: Turismo e prostituição na ótica de travestis em Natal/RN, Brasil
}

\author{
Destiny of Sex: Tourism and prostitution through the
} travestis' vision in Natal/RN, Brazil

\section{Ricardo Lanzarini}

Professor Adjunto do Departamento de Turismo e Professor Permanente do Programa de Pós-Graduação em Turismo (PPGTUR) da Universidade Federal do Rio Grande do Norte UFRN, Natal/RN, Brasil

E-mail: ricardolanzarini@gmail.com

\section{Kauay Vinícios Gurgel}

Bacharel em Turismo pela Universidade Federal do Rio Grande do Norte - UFRN, Natal/RN, Brasil

E-mail: kauaygurgel@gmail.com

\section{Michel Jairo Vieira da Silva}

Professor e coordenador do curso de graduação em Turismo da Universidade Federal do Rio Grande do Norte - UFRN, Natal/RN, Brasil

E-mail: micheljvs@hotmail.com 


\section{RESUMO}

Desde o final dos anos 1990 a prostituição de travestis na cidade de Natal/RN atende ao mercado turístico, especialmente pelas ruas do bairro de Ponta Negra, mas também por toda a cidade, como uma atividade marcante. Então, esta pesquisa tem por objetivo compreender a dinâmica social entre a prostituição de travestis e o fenômeno turístico na cidade de Natal/RN, a fim de identificar o perfil dessas travestis e dos espaços utilizados por elas, além do perfil de turista que consome esses serviços. A trajetória metodológica contou com uma abordagem qualitativa sobre o depoimento de seis travestis e foi desenvolvida por meio de uma pesquisa exploratória-descritiva entre julho de 2017 e maio de 2018. Após a realização das entrevistas semiestruturadas, foi possível considerar que o perfil das entrevistadas tem semelhanças de faixa etária e de conflitos sociais em virtude da identidade de gênero, fato que as aproxima sob o prisma do preconceito e marginalidade, mas com disparidades em relação à escolaridade e renda, o que as distancia em relação ao consumo de bens e poder aquisitivo, seleção do perfil de público e local que atendem. Já o perfil da clientela turística é, quase sempre, de homens casados e de meia idade provenientes, majoritariamente, do continente europeu.

Palavras-chave: Prostituição. Turismo. Travestis. Natal/RN. Identidade de Gênero.

\section{ABSTRACT}

Since the end of the 1990's prostitution of travestis in the city of Natal/RN has served the tourist market, especially in Ponta Negra's neighborhood, but also throughout the city, as a remarkable activity. The purpose of this research is to understand the social dynamics between the travestis' prostitution and the tourist phenomenon in the city of Natal/RN, in order to identify the profile of these travestis and the spaces used by them, as well as the tourist profile that consumes these services. The methodological trajectory counted on a qualitative approach on the interviews of six travestis and was developed through an exploratory and descriptive research between July 2017 and May 2018. After conducting the semi-structured interviews, it was possible to consider that the profile of the interviewees has similarity in age range and social conflicts due to gender identity, a fact that approaches them from the perspective of prejudice and marginality, but with disparities in relation to schooling and social class, which distance them in relation to the consumption level and the purchasing power, selecting the audience and location profile they serve. In addition, the tourist's profile is almost always married, in middle-aged and mostly from Europe.

Keywords: Prostitution. Tourism. Travestis. Natal/RN. Gender identity. 


\section{INTRODUÇÃO: QUANDO O TURISMO PRECISA FALAR SOBRE “ELAS”}

O turismo é uma das principais economias do Rio Grande do Norte (RN), com destaque para sua capital Natal, que concentra o maior número de leitos e investimentos no setor. De acordo com a Inframérica, o Aeroporto Aluízio Alves, em São Gonçalo do Amarante, teve uma movimentação superior a 2.403.677 de passageiros durante todo o ano de 2017, o que representa um crescimento de 3,8\% em relação a 2016. Já a Superintendência Regional da Polícia Federal do RN destaca que, em janeiro de 2018, houve um aumento de $69,41 \%$ de turistas internacionais em relação ao mesmo período no ano de 2017 , fatos que comprovam a crescente demanda turística, que já representa um aumento de aproximadamente R \$ 15 milhões na economia estadual. Em consonância, conforme pesquisa realizada pelo IPDC (Instituto de Pesquisa e Desenvolvimento do Comércio) em parceria com a Federação do Comércio de Bens, Serviços e Turismo do Rio Grande do Norte (Federação do Comércio do Rio Grande do Norte [Fecomércio]) no ano de 2017, constatou-se que dos turistas estrangeiros que mais visitam Natal, argentinos e italianos são os maiores públicos, representando, respectivamente, $7,7 \%$ e $1,7 \%$ do total de turistas.

A partir desses dados e compreendendo a dinâmica turística de Natal, o bairro de Ponta Negra se destaca como área funcional turística ${ }^{1}$, sendo o principal lugar de encontro de visitantes e visitados. Mas, além deste bairro, estão na rota dos turistas as praias urbanas de Areia Preta, dos Artistas, do Meio, do Forte, Redinha, bem como regiões não praieiras, menos turistificadas e mais cotidianas da cidade, como o centro comercial e histórico de Natal. Nesta circulação, eles exercitam e exibem sua identidade turística, distinção cultural e seus traços, sejam por meio da sua fisionomia ou através de suas expressões, sotaques, gírias e vestes. Destaca-se no transitar pela cidade também pelo seu poder aquisitivo: na condição de visitante o sujeito está disposto a gastar com ofertas vinculadas às motivações principalmente de "sol e praia", mas também de aventura, eventos, cultura, compras, bem como com prazer sexual, alimentando o mercado do sexo nos destinos turísticos do mundo todo, sendo o Nordeste brasileiro um dos mais preferidos destinos de estrangeiros.

O sexo, como entretenimento, tornou-se um negócio cada vez mais profissionalizado e lucrativo, oferecido na forma de diversos produtos e serviços: filmes, fotos, sites na internet, casas de "massagem", saunas, bares, boates, casas de prostituição

\footnotetext{
1 "Área geográfica distinta dentro de uma área urbana mais ampla, caracterizada por uma concentração de usos do solo dedicados ao turista, atividades e visitação, com fronteiras bastante definidas. Essas áreas funcionais geralmente possuem um caráter distinto em virtude de sua mistura de atividades e do uso da terra, tais como restaurantes, atrações e vida noturna, seu tecido físico ou arquitetônico, especialmente o domínio de edifícios históricos, ou sua conexão a um grupo cultural ou étnico particular dentro da cidade" (Hayllar \& Griffin, 2005, p. 517, como citado em Hayllar, B, Grirrin, T., \& Edwards, 2011, p. 04).
} 
convencionais, anúncios em jornais, viagens, sex-shops, hotéis e motéis são alguns dos negócios legais envolvidos no mercado sexual. Há ainda o campo da ilegalidade onde proliferam a cafetinagem, exploração e tráfico de pessoas, tráfico de drogas, extorsão, violência física, lavagem de dinheiro e outros negócios ilícitos que, em um mundo onde o crime também é globalizado, perpassam os negócios do sexo, mercado financeiro, corrupção ativa e passiva (Trigo, 2007, p. 02).

Nos anos 2000, a prática da prostituição vinculada ao fenômeno turístico em Natal chegou a ser notícia nos principais veículos de comunicação do país (Tribuna do Norte, 2011; Jornal O Globo, 2006; G1, 2011), gerando impacto negativo em outros segmentos de interesse turístico, com o afastamento de turistas de lazer e residentes de áreas específicas do bairro de Ponta Negra em que se concentrava a prostituição. Contudo, essa prática tem se tornado mais clandestina, ficando longe dos olhos cotidianos de residentes e turistas que viajam em família ou grupos, sem desconsiderar que ainda haja espaços de prostituição e pessoas nas ruas que concentram o fluxo turístico.

As pessoas que se prostituem nas ruas são, em sua maioria, sujeitos sociais vulneráveis, normalmente desempregados e expostos à violência, incluindo majoritariamente mulheres, homens e travestis, que compreendem o universo dessa análise, a fim de identificar a forma como a prostituição de travestis dialoga com o setor turístico na cidade do Natal/RN, além de traçar o perfil das travestis envolvidas com a atividade da prostituição, apresentando os espaços mais utilizados e as características dos clientes-turistas.

\section{SEXO E PROSTITUIÇÃO: UMA CONTEXTUALIZAÇÃO}

Prostituição é um termo que vem do latim prosto, que quer dizer "estar às vistas, à espera de quem quer chegar ou estar exposto ao olhar público" (França, 2012, p. 145). É uma atividade que se estabelece através da relação sexual em que há cobrança monetária ou vantajosa (jóias, perfumes, viagens, celulares) de uma das partes, sendo a monetária a mais comumente praticada no atendimento a turistas, não possuindo restrições de identidades de gênero e sexualidades. No Brasil esse tema notadamente se manifesta (com destaque para estrangeiros) a partir de um imaginário de luxúria e perversão, aliado à nudez feminina em um Éden tropical, crendo não existir "pecado do lado de baixo do Equador” (Buarque, 1973). Esse imaginário está alimentado pelas mais diversas linguagens artísticas e publicitárias (literatura, música, artes plásticas, cinema, cartões postais, propagandas publicitárias turísticas, por exemplo) veiculadas no país e no exterior, que vendem o Brasil como destino exótico e sensual.

Olivieri e Villa (1999) afirmam que a imagem de um Brasil associado a uma atmosfera paradisíaca, tropical e libidinosa que começou a ser construída ainda com a chegada dos 
portugueses que, em 1500, encontraram um território habitado pelos índios brasileiros, que andavam nus e viviam livremente pelas florestas, fato que despertou uma fetichização da imagem do "selvagem brasileiro" pelo europeu. Cavalcante (2011, p. 41) analisa a carta de Pero Vaz de Caminha e afirma que: "ele não apenas descreve seus corpos [das mulheres], como também os admira, chegando a desculpar-se com o rei, tamanha era a carta e de tão rica em pormenores". A autora reforça que, desde o seu descobrimento, o Brasil é percebido pelos estrangeiros como um paraíso perdido e exuberante, tanto em relação a sua natureza quanto nos costumes e beleza natural de seus habitantes (Cavalcante (2011, p. 42). Outrossim, reafirma a ideia de Gabrielli (2006) ao enfatizar que mesmo o Brasil, já no período da colonização, tinha sua imagem correlacionada ao paradisíaco e mesmo que anos tenham se passado, é uma palavra muito marcante nas associações feitas por diversas pessoas ao redor do mundo, especialmente quando se fala de turismo.

Muitos são os tabus existentes no mundo da prostituição. Em alguns países, por exemplo, a atividade é legal e assimilada em uma perspectiva de mercado (Red Light District, Amsterdã), mas ainda há locais onde é considerada um delito, cabível de punição tanto para quem oferta quanto para quem consome. É o caso de países como Andorra, Bósnia e Herzegovina, Eslovênia, Geórgia, Lituânia, Romênia, Sérvia e Suécia. Já em alguns outros, as penalidades são aplicadas apenas para os agenciadores (caso da realidade brasileira), os populares "cafetões e cafetinas", e também para as pessoas que fazem esse tipo de oferta em vias públicas, quando configurado como atentado ao pudor.

Há vertentes do mundo da prostituição que adentram na criminalidade, como é o caso do tráfico de pessoas, em que mulheres, homens e travestis são ludibriados, sequestrados e encaminhados para outros países e continentes para o exercício da prostituição como trabalho escravo. De acordo com o Parlamento Europeu (2016), o número de pessoas traficadas alcança 21 milhões, gerando uma movimentação por ano de cerca de 117 bilhões de euros. Além disso, é importante ressaltar um dado fornecido pelo Escritório de Estatística da União Europeia, que indica que desse total de pessoas traficadas, $22 \%$ eram exploradas sexualmente.

Sobre os corpos a serem vendidos e consumidos, seja consentido, seja obrigado, destaca-se a busca por padrões de beleza e desejo que alimentem a prostituição de todos os gêneros. Percebe-se que o corpo humano, com o passar do tempo, tem ganhado mais notoriedade nas mídias por meio de estereótipos de beleza. A busca pelo peso ideal, músculos bem definidos, cabelo, pele, seios e nádegas admitidos por um olhar social cruel, além de ser uma questão de saúde, em muitos casos, é também uma questão estética, de aceitação pública e de ego, além de ser um fator competitivo de venda. Receber elogios e olhares de desejo é 
apenas um dos potencializadores da vaidade humana que, no caso da prostituição, é enfatizado ainda mais pelo uso do corpo como mercadoria. Nessas relações comerciais, a "embalagem" deve se manter bem cuidada para que o "produto" esteja cada vez mais valorizado, tornando o preço cobrado pelo programa cada vez mais caro.

Nessa relação o preço é definido após uma oferta de valor atraente que, somado aos altos investimentos feitos na busca do corpo perfeito, permitem negociações. É necessário destacar a diferença existente entre preço e valor para que se compreenda as suas reais aplicações:

O preço é uma medição quantitativa da importância relativa de um dado objeto, geralmente expresso em uma quantia específica de dinheiro. O valor, por sua vez, não apenas se expressa no preço, mas transcende-o, pois abarca elementos qualitativos que através do dinheiro e do preço são expressos quantitativamente (Russo, 2006, p. 31).

A troca do prazer por dinheiro está relacionada simbolicamente com muitos outros aspectos como autonomia pessoal, sobrevivência (comumente associado às travestis que têm dificuldade de acesso ao mercado de trabalho formal) e posicionamento social, além de poder de consumo que "representa o tipo de sociedade que promove, encoraja ou reforça a escolha de um estilo de vida e uma estratégia existencial consumista, e rejeita todas as opções culturais alternativas" (Bauman, 2008, p. 71).

Nesse sentido, é compreensível quando garotas e garotos de programa relatam que preferem que o pagamento seja apenas em dinheiro (e não em bens de valor ou "presentes", como joias ou roupas). E, nesse processo de troca, o dinheiro facilita o contato e compras de objetos e/ou pessoas, relacionando os aspectos tangíveis do consumo com os aspectos intangíveis, ou seja, aquilo que está invisível e muito mais subjetivo, relacionado com as emoções, sentimentos e experiências que o aspecto tangível proporciona.

\section{PROSTITUIÇÃO E TURISMO}

Embora o "turismo sexual" não seja compreendido como um segmento do setor, a Organização Mundial do Turismo (OMT, 1995 como citado em Assunção \& Babinski, 2010) entende essa prática como

(...) viagens organizadas dentro do seio do setor turístico ou fora dele, utilizando, no entanto, as suas estruturas e redes, com a intenção primária de estabelecer contatos sexuais com os residentes do destino, onde o motivo principal de pelo menos uma parte da viagem é o de se envolver em relações sexuais. Este envolvimento sexual é normalmente de natureza comercial. 
Dutra (2008) acredita que o "turismo sexual" é formado por "viagens organizadas que utilizam as estruturas da indústria de turismo com os fins principais de facilitarem o comércio sexual entre turistas e nativos". Já Leite (2007) destaca que essa prática em viagens é baseada em relações de desigualdade entre países que reproduzem ideologias e práticas racistas e sexistas que reafirmam diferenças sociais, econômicas, políticas e culturais. Suas características incluem o deslocamento de homens e mulheres para outros lugares (cidades, estados e países), em busca, exclusivamente, de aventuras eróticas.

Cabe destacar que o turismo associado ao sexo pago não se limita aos turistas estrangeiros nem aos grandes centros urbanos do litoral brasileiro. Também é comum encontrar serviços sexuais em cidades do interior, vilarejos e regiões isoladas, sendo nestes casos, uma atividade consumida por trabalhadores viajantes, como caminhoneiros, por exemplo. E, a utilização do mercado do sexo pelo turista nem sempre remete a uma viagem de cunho sexual, isto porque pode haver outras motivações principais, sendo o sexo consumido como uma atividade de entretenimento, nas horas vagas.

Sobre o turista estrangeiro que busca sexo pago no Nordeste brasileiro, alguns trabalhos vislumbram essa realidade, especialmente a partir dos anos 2000, em que cresceu muito o número de turistas de diversas partes do mundo, tal qual destacam Bem (2005) e Assunção (2009). Os principais contribuintes para esse expressivo número de turistas são: o fato de o Nordeste possuir a maior parte da costa litorânea do país, uma natureza rica e diversificada, um clima tropical e agradável o ano todo, a hospitalidade de seu povo e as desigualdades sociais e econômicas que potencializam o mercado do sexo como uma oportunidade de ganhos para os residentes.

A Região Nordeste apresentou um processo considerável e relativamente rápido de modernização devido ao desenvolvimento turístico, propiciando a restauração de centros e bairros antigos em cidades como Salvador (BA), Natal (RN), Recife (PE) e Fortaleza (CE), revalorizando e ressignificando esses espaços em prol do turismo (Bem, 2005). Alinhada a essa melhoria da infraestrutura, ainda permaneceu por muito tempo a publicidade institucional e privada do produto turístico com um apelo erotizado do corpo e sensualidade brasileira, fortalecendo ainda mais as conexões do Brasil ao sexo. De acordo com Bignami (2002, p. 39):

A formação da identidade nacional está inteiramente ligada à projeção da imagem do país no exterior e à aceitação do elemento exótico como parte da própria autoimagem. (...) A imagem nacional não é resultante unicamente da visão do estrangeiro a respeito do país, embora exista uma tendência a se analisar a situação somente sob esse aspecto. O Brasil e o brasileiro parecem se interessar muito mais pelo que se diz no exterior do que pela própria formação interna do país, responsabilizando o estrangeiro pelo que o país é. 
Tal afirmação pode ser comprovada quando se toma como exemplo a construção da “identidade nacional”, que está ligada aos vários anos de campanhas turísticas sobre o Brasil como "país do carnaval", fazendo uso dos corpos como alegoria e fetiche para sedução do turista como um país sexualmente livre. Trigo (2007) ressalta que o estereótipo de país quente e sensual marcou a imagem externa da nação e que os cenários brasileiros, apesar de estereotipados, são valorizados a partir dessa realidade.

Bem (2005) destaca que a forma de turistificação utilizada na gestão pública e privada do Brasil gera segregação e exclusão da comunidade receptora, causando, inclusive, o empobrecimento de algumas camadas da população local. As formas de ocupação do território, além das novas atribuições e funcionalidades do espaço, expulsam de maneira gradativa os moradores porque ficam à margem da produção do turismo (Assunção, 2009). Nesse contexto, o morador acaba tendo basicamente duas opções: buscar por outros espaços para morar ou passar por um processo de adaptação às novas possibilidades de ocupação profissional, seja de modo formal ou informal. Portanto, é comum, nos espaços turísticos, que uma parcela da população local ofereça serviços sexuais para os turistas como mecanismo de manutenção da vida cotidiana (Bem, 2005).

Muitos jovens (entre eles, as travestis) entram no mundo da prostituição para servir o turista em busca de sobreviver a uma realidade pouco amistosa, atentos ao "sonho de casamento", acreditando que o turista estrangeiro seja um "príncipe encantado" que possa proporcionar uma vida melhor em outro país e realização de muitos sonhos, tal qual discorre Piscitelli (2005) e Carvalho (2006). Dessa forma, compreende-se que o sexo pago associado ao turismo, além de uma relação mercadológica, pode envolver uma relação de encantamento e criação de vínculos entre os pares que, por vezes, retornam ao Brasil.

Sobre a organização do mercado do sexo para atender o turista, Leite (2007) destaca que pode ser dividido em dois aspectos: primeiro, por pacotes que são comercializados pelas agências nacionais e internacionais e apresentam diversas mulheres, em sua maioria jovens, como sendo mais um atributo a ser desfrutado com a compra do pacote turístico; segundo, pela oferta informal, cujo agenciamento acontece nos próprios hotéis, além de bares, casas noturnas, barracas de praia, taxistas, casas de massagem ou até mesmo na abordagem direta nas ruas.

Bem (2005, p. 33) acredita que nas últimas décadas surgiram "várias agências de 'matrimônio' e agências de viagens especializadas em oferecer pacotes completos, incluindo acompanhantes permanentes durante as férias dos turistas”. Esses acompanhantes, seja por meio de agenciamento ou numa perspectiva informal, sempre foram majoritariamente 
mulheres, mas, hoje, é muito comum também a presença de homens e travestis (em menor escala), que se especializam em atender ao turista, falando vários idiomas e sabendo se portar nos mais variados ambientes.

\section{O CASO DAS TRAVESTIS}

A fim de aumentar o número de viagens pelo Brasil, bem como atender segmentos turísticos diversos como o das pessoas idosas, com deficiência ou com mobilidade reduzida e LGBTI+ - lésbicas, gays, bissexuais, transgêneros, intersexuais e demais segmentos, o Plano Nacional de Turismo 2013-2016 propôs a formulação de políticas públicas de fomento do turismo, a exemplo dos guias de bolso (Dicas para atender bem turistas LGBT) ${ }^{2}$ de modo a orientar a prestação especializada de serviços turísticos, objetivando um melhor atendimento ao cliente/turista.

No caso das travestis, quando são garotas de programa, tendem, quase sempre, a ficarem marginalizadas por um duplo preconceito, seja por sua identidade de gênero, seja por trabalharem com o mercado do sexo. De acordo com a ONG Transgender Europe (2017, como citado em Mott \& Michels, 2017, p. 14) há 14 vezes mais chances de uma pessoa trans ser assassinada do que um homem gay cis e se comparado as 144 travestis brasileiras assassinadas diante de 21 trans americanas, as brasileiras têm 9 vezes mais de chances de sofrerem morte violenta, fato que as coloca em uma condição de risco constante, especialmente quando estão trabalhando nas ruas.

Entrando no aspecto conceitual, o guia apresentado no ano de 2016 traz a definição de identidade de gênero como sendo o reconhecimento do indivíduo dentro dos padrões de gênero: feminino e masculino. As pessoas cisgêneras são aquelas que se identificam com o gênero igual ao do sexo de nascimento, enquanto que as transgêneros são aquelas que se identificam com um gênero diferente ao do sexo de nascimento e que não necessitam obrigatoriamente alterar seus corpos com uso de hormônios ou adequações cirúrgicas. Assim, as travestis, que nasceram com o sexo masculino, se identificam com o gênero feminino, exercendo este papel socialmente. Contudo, não chegam a fazer a cirurgia de redesignação sexual, justamente, por ter o seu pênis como objeto de desejo e fetiche de muitos de seus clientes sexuais.

Dentre esses clientes, os turistas se destacam por estarem em trânsito e supostamente com dinheiro para gastar, sem vínculos cotidianos, muitas vezes, livres das obrigações

${ }^{2}$ Recuperado de http://www.turismo.gov.br/images/pdf/CartilihaLGBT145x105cm_WEB.PDF 
familiares e sociais que regulam seus comportamentos, inclusive sexuais. Lanzarini (2016, p. 29) afirma que a mobilidade compõe um dos principais eixos de relações humanas e, a partir das motivações dos viajantes, "geram possibilidades de socialização momentâneas e privadas para além do sistema social de pertencimento". Então, a condição de viajante permite ao turista anular hábitos, costumes e práticas que lhe convém para deixar aflorar o que estava reprimido, dando-lhe uma sensação temporária de liberdade, que pode ser canalizada para a liberação de desejos sexuais que certamente seriam condenados por seu grupo social de origem, a exemplo das práticas homossexuais, como relata o autor ao apresentar o conceito de "zonas livres": espaços simbólicos em que ocorrem as rupturas e as sociabilidades homoeróticas de homens heterossexuais durante viagens a trabalho. Tal afirmação se torna ainda mais relevante quando se constata, nos discursos apresentados pelas travestis, que a maioria dos seus clientes turistas são homens socialmente reconhecidos como heterossexuais, fato que reforça a teoria das zonas livres proporcionada pelas grandes cidades com a sensação de ausência da vigilância social.

As relações sexuais pagas, em foco neste texto, acontecem no "submundo" (termo utilizado por uma das travestis entrevistadas) do sexo, de forma velada, reafirmando uma dominância da heteronormatividade que considera inaceitável a prática sexual com "homens vestidos de mulher" e também a passividade sexual masculina (associado à feminilidade) como inferior, uma fraqueza que vai contra a "natureza do homem" de ser sempre macho, forte e reprodutor.

\section{METODOLOGIA: BUSCANDO DEPOIMENTOS}

Esta é uma pesquisa fenomenológica de caráter qualitativo, por não se preocupar com a representatividade numérica, mas, sim, com o aprofundamento do entendimento a respeito de um grupo social específico. A natureza da pesquisa é vinculada à experiência do sujeito estudado e não em verdades preestabelecidas, objetivando trazer a discussão de uma temática contemporânea. A proposta aqui foi de ouvir e interpretar o olhar das travestis sobre o turismo baseado em uma preocupação "com a descrição da experiência tal como ela é. A realidade é construída socialmente e entendida como o compreendido, o interpretado, o comunicado" (Otani \& Fialho, 2011, p. 27).

A abordagem é descritiva-exploratória, uma vez que objetiva "proporcionar familiaridade com o problema, no intuito de torná-lo mais explícito" (Gil, 2002, p. 41), bem como propicia um aprofundamento descritivo do objeto de pesquisa. Desse modo, faz uso de levantamento biográfico e entrevistas com pessoas que tiveram experiências práticas com o 
problema pesquisado: fatos e fenômenos do cenário de prostituição de travestis na atividade turística em Natal.

A pesquisa utilizou-se de entrevistas semiestruturadas com 06 travestis que atuam na prostituição em Natal e que têm experiências com clientes turistas (sejam nacionais ou internacionais). Para facilitar aproximação com os sujeitos, realizou-se inicialmente uma busca por representantes de ONGs que apoiam a causa LGBT em Natal, seguido de contato direto com possíveis entrevistados. Esse processo de aceite por parte das travestis em participar da pesquisa foi bastante lento, tendo em vista a resistência natural que elas apresentam em terem seus relatos expostos em um trabalho acadêmico e de acreditarem que normalmente os pesquisadores não retornam com os resultados das pesquisas, ou que não são solidários aos problemas enfrentados pelo grupo, potencializando o sentimento de preconceito que sofrem cotidianamente. Assim, foram contatadas mais de 20 pessoas, tendo a adesão de 06 respondentes, que concederam as entrevistas entre maio e junho de 2018.

\section{ANÁLISE DOS RESULTADOS: O TURISMO NA ÓTICA DAS TRAVESTIS}

As travestis entrevistadas atuam na cidade de Natal/RN. Para fins didáticos e preservação do sigilo da identidade, as entrevistadas são identificadas como: Garota 1 (G1), Garota 2 (G2), Garota 3 (G3), Garota 4 (G4), Garota 5 (G5) e Garota 6 (G6), com o perfil que segue descrito:

G1 - 31 anos, iniciando o travestismo aos 23 anos. Mora na Zona Norte (Igapó) e é natural da cidade Assú/RN. Formada em Administração, exerceu a profissão por apenas 01 ano. Veio de família de classe média e saiu de casa quando resolveu adequar o corpo ao seu gênero. Disponibiliza seus serviços através de sites e só atende em motéis e hotéis.

G2 - com 19 anos, mora na Zona Norte (Nova Natal) e é natural de Arez/RN. Tem ensino superior incompleto em Administração e atende em local próprio.

G3 - 28 anos, iniciando o travestismo aos 20 anos. Mora no bairro das Quintas e atende na Cidade da Esperança. É natural de Natal/RN e possui o ensino médio completo. Atende em seu próprio local, podendo cobrar bem mais do que cobraria se estivesse na rua.

G4 - com 26 anos, iniciou o travestismo aos 22 anos quando se afastou do trabalho devido ao preconceito. Mora na Zona Norte (Igapó) e atende preferencialmente em local próprio. É natural de Natal/RN e possui ensino superior incompleto.

G5 - Se descobriu aos 06 anos de idade e começou o travestismo aos 18 anos. É natural de Natal/RN e atualmente mora e atende em São Paulo/SP, mas quando vem a Natal atende também. Possui ensino médio incompleto. 
G6 - com 30 anos, começou a se travestir aos 13 anos. Mora no bairro de Santarém (Conjunto Potengi) e atende em local próprio. Possui ensino fundamental incompleto.

Apesar das dificuldades enfrentadas ao longo de sua história de vida, tanto pela identidade de gênero quanto pela atual profissão, todas elas possuem sonhos e perspectivas futuras de largar a prostituição e consolidarem os seus projetos de vida, que incluem uma vida mais digna, sendo respeitadas e aceitas pela sociedade.

\subsection{Apresentação dos espaços e características dos clientes}

A aproximação do cliente-turista é, talvez, o maior de todos os desafios de uma pesquisa desse gênero, dado os limites morais que mantém as práticas do sexo comercial na clandestinidade. Logo, as informações coletadas sobre o perfil do turista que aqui são apresentadas têm como fonte apenas os relatos das entrevistadas. A respeito dos clientes (turistas) que buscam os serviços dessas acompanhantes na cidade de Natal/RN, elas apontam serem oriundos de diversas partes do mundo, especialmente do continente europeu, com destaque para a Itália, seguida de Holanda, Alemanha e Portugal.

No que se refere à idade, elas atestam uma faixa etária média com variação entre 30 e 50 anos. Em adição, relatam que, na grande maioria dos casos, esses turistas são casados e buscam satisfazer fantasias que suas mulheres não aceitariam, conforme evidenciado:

- A maioria são homens casados com boa vida financeira e uma imagem perfeita de pai, alguns com posição política e religiosa, mas segundo os mesmos, as trans satisfazem desejos que suas esposas jamais topariam ou que lhes pareceriam homossexuais dentro da sociedade normativa onde vivem $(\mathrm{G} 1,2018)$.

- Geralmente $96 \%$ deles são casados ou tem algum tipo de relacionamento com mulheres cisgênero $(\mathrm{G} 3,2018)$.

- Na grande maioria são casados. Mas também tem aparecido muitos solteiros, assim como, já sai com virgem que queria ter experiência antes de sair com a parceria para no ato o desempenho ser satisfatório $(\mathrm{G} 4,2018)$.

Entendendo que a maioria dos seus clientes são homens que adotam uma postura heteronormativa no cotidiano, questionou-se a respeito das principais fantasias sexuais desses turistas durante suas estadas em Natal/RN e, como resultado, foi apontada a externalização da sexualidade sem as pressões morais impostas aos desejos considerados feminizados.

- A grande maioria gosta mesmo de usar peças íntimas nossas, acho que esse fetiche é o mais comum! É estranho quando eles pedem para serem maquiados e usam nossas vestes e saltos, ainda fazem pequenos vídeos no momento do programa e salvam para eles mesmo depois se masturbar em casa $(\mathrm{G} 1,2018)$.

- O desejo mais comum é ser dominado, penetrado, mas existem milhares de coisas (...) o cara todo engravatado me levou para o motel, me deu a chave do quarto e em 
questão de pouquíssimos minutos ele entrou no quarto de espartilho, cinta liga e salto alto, todo peludo e barbudo (G4, 2018).

- Pediu para fazer muitas coisas, tipo: tirar sandália e dar nele ou botar minha peruca ou vestir minha roupa também. Botar minha calcinha, meu tamanco, a sandália que eu estiver usando ou querer que eu maquie eles, entendeu? (G6, 2018).

Nesse contexto, observa-se que os discursos dialogam diretamente com o conceito de “zonas livres” apresentado por Lanzarini (2016), mostrando que os espaços são criados de maneira simbólica, proporcionando uma maior liberação moral e familiarização de homens heterossexuais com o universo homoerótico durante o curto espaço de tempo da viagem. Dessa maneira, o turista passa a sentir uma sensação de liberdade ligada à viagem e ao grande centro urbano incitando a um comportamento liminar, um fazer tudo em demasia, justamente porque não lhe é próprio no dia a dia.

O autor destaca, ainda, que as grandes cidades estimulam o comportamento sexual de turistas devido à invisibilidade social. Dessa forma, a dinâmica da busca sexual em destinos turísticos se constitui numa relação proporcional à grandeza do espaço urbano. Sentir-se vigiado e moralmente cobrado passa a ser inverso ao tamanho do grande centro. G3 (2018) observa que "é normal eles nos procurarem mesmo morando aqui, porém os que estão em viagem se sentem mais a vontade de nos abordar em qualquer lugar”.

Sobre a vigilância existente nas cidades de origem, entende-se que muitos desses turistas prezam por manter posturas mais tradicionais de comportamento heteronormativo devido a questões familiares e desvalorização de sua figura profissional, mantendo-se no "armário", que Almeida (2009) aponta como a fase da vida em que não se assume a identidade e as práticas sexuais, salvaguardando-se dos estigmas sociais da sexualidade. É por isso que essas práticas de cunho sexual devem acontecer "no sigilo", quase que em um mundo paralelo, criado unicamente para a realização de fantasias que gerem prazer sexual esporádico e anônimo.

Ao serem questionadas sobre as profissões de seus clientes, as garotas são enfáticas ao afirmarem que trabalham com a discrição e evitam saber tantos detalhes da vida pessoal dos homens que as procuram, a não ser que eles mesmos se abram por vontade própria ou pelo fato de serem figuras públicas.

- Muitos são empresários, mas aparecem trabalhadores até assalariados tipo vendedores, profissionais liberais entre outros. O mercado é bem amplo, principalmente aqui no Nordeste. No Sul aparecem mais empresários, mas aqui aparece tudo $(\mathrm{G} 1,2018)$.

- A profissão deles eu não procuro saber, mas eu já fiquei com médico, advogado, psicólogo, detetive, policial, barman, pedreiros, donos de empresa (G2, 2018). 
- A profissão é variada, desde um executivo, advogado, mestre de obra, como também pessoas públicas e globais. Eu mesma já sai com um ator conhecido da emissora globo $(\mathrm{G} 4,2018)$.

Percebe-se que as profissões são variadas e muitas apresentam certo status social ou confrontam a imagem social do "machão" (pedreiro, policial, etc.). No caso de estrangeiros, as informações também são limitadas pela língua, pois as entrevistadas atestam desconhecimento de outros idiomas. Há, ainda, um código de conduta entre elas que garante o anonimato dos clientes, de modo que eles se sintam seguros e possam retornar a usar dos serviços.

Em relação aos valores cobrados, as garotas apresentam uma diversidade de ofertas, seja para o turista (que costuma pagar um pouco mais caro sem reclamar do preço), seja para o residente (que sempre tende a barganhar o valor).

- Eu cobro R \$200,00 por duas horas, mas nunca eles ficam o tempo todo. Saem bem rápido e, quando aparece um que queira algo mais longo, chego a cobrar $\mathrm{R} \$ 600,00$ por pernoite... Mas na rua já cobrei até $\mathrm{R} \$ 30,00$. A situação melhorou há alguns anos depois dos sites. Antes, quando era só na rua, só dava mixaria, máximo da noite era $R \$ 150,00(\mathrm{G} 1,2018)$.

- Olha, o valor do meu programa é totalmente relativo, entendeu? Ele vai depender do cliente, na verdade, com quem eu estou saindo, mas é em torno de $R \$ 100,00$ (G2, 2018).

- O programa é cobrado entre $\mathrm{R} \$ 80, \mathrm{R} \$ 90, \mathrm{R} \$ 70$. Depende muito da hora e do que eles queiram fazer $(\mathrm{G} 6,2018)$.

Há uma variação no valor cobrado pelos serviços sexuais que está diretamente relacionado ao investimento em estética, mas, também, ao nível de escolaridade. Tomou-se como base os relatos de G1, que possui o ensino superior completo e valores dos seus serviços são os mais caros se comparado ao das outras garotas; G2, que iniciou o seu ensino superior, muito embora não tenha concluído e os valores dos serviços são considerados medianos; e G6, que tem apenas o ensino fundamental e cobra os valores mais baratos. Este fato demonstra que o grau de escolaridade da travesti é determinante para o perfil de cliente que será captado. Em adição, a mesma respondente que cobra os valores mais baixos é a única que relata problemas com drogas envolvendo turistas, como apresentado no relato abaixo:

- O problema deles é que são muito envolvidos com a droga e isso, para mim, não é legal, entendeu? Nunca gostei muito, apesar de que têm muitas travestis que se envolvem por causa dos clientes e acabam no mundo da droga. Então, o problema do turista, para mim, é sempre que eles trazem muita droga para esse lado da prostituição $(\mathrm{G6}, 2018)$. 
Este relato evidencia que algumas travestis acabam adentrando no mundo das drogas devido ao fato de seus clientes serem usuários frequentes que as utilizam especialmente durante o ato sexual como forma de potencializar o prazer, incentivando que elas também utilizem como uma receita de felicidade (o que é muito atrativo para alguém que tem uma vida social cheia de privações e estigmas). Além disso, G6 destaca que a Avenida Roberto Freire (principal eixo urbano do turismo) é o principal ponto de prostituição para travestis, mesmo havendo uma série de problemas com crimes praticados pelas próprias meninas, que costumam roubar e aplicar golpes em seus clientes. G6 destaca que trabalhou nesse endereço por cerca de 5 anos, mas que, de modo geral, as travestis que dominam esse espaço têm condutas pouco honestas com os clientes-turistas, depreciando a imagem das outras.

Partindo da Avenida Roberto Freire, as garotas foram questionadas a respeito dos espaços em que essas práticas ocorrem, como os turistas chegam até elas e para onde costumam ir para a realização do programa. Nos depoimentos identificou-se que a prática mais comum é usar da Internet como forma principal de contato, embora algumas ainda fiquem à mostra pelas ruas, mesmo que mais sujeitas à violência e intolerância.

- Eu só atendo com hora e dia marcado. Sempre em motéis, eles me buscam ou pagam Uber para eu chegar lá. Para não levar calote, eles pedem e pagam, mas antes de ir eu pego número do quarto, ligo para o motel para saber se realmente está ocupado e depois que confirmo tudo saio de casa. Dá para fazer uns 5 por semana (G1, 2018).

- Bem, 90\% dos meus clientes vêm por anúncio. Geralmente aparecem nas ruas, mas é mais fácil pelo anúncio que é onde eu tenho toda minha divulgação (G2, 2018).

- As que trabalham na rua, geralmente fazem ponto perto de motel, mas $80 \%$ preferem terrenos baldios (G3, 2018).

- Através de anúncios em sites gratuitos e pagos! Há também um grupo local num fórum onde trocam experiências e informações e fazem indicações. Também tem sempre aquele que compartilha a experiência com um amigo que desperta o interesse e entra em contato. Já aconteceu de ser abordada na rua, como também, em festas e pedirem meu contato para solicitar meu serviço (G4, 2018).

- Eles me procuram muito através de site ou quando ando na rua (G5, 2018).

- Geralmente, quando eu estou na rua, os clientes chegam, se aproximam, de carro, de moto, a pé (G6, 2018).

Apesar de existirem meios mais sigilosos e menos vulneráveis para a prática de atividades sexuais, a rua ainda é um local comum para a prática de prostituição, muito pelo fato de facilitar as relações comerciais e de negociação dos corpos.

As garotas ainda destacam os locais mais comuns para onde são levadas para a realização dos seus programas: algumas possuem local próprio, com pouco fluxo de pessoas e 
transportes, tendo a discrição como parte da oferta; e a maioria destaca que os motéis são o principal espaço para essas atividades sexuais (na Avenida Roberto Freire há anúncios e placas de direção de alguns motéis que ficam nas ruas laterais). Além desse meio de hospedagem tradicionalmente utilizado no Brasil para o sexo, elas salientam que também atendem no próprio carro dos clientes ou em suas casas, bem como em terrenos baldios e locais públicos sem movimento, colocando-se o tempo todo em risco.

Foi destacado, também, que a hotelaria é um forte ponto de prestação de serviço sexual, entretanto, devido a episódios de vandalismo e extorsões de clientes no passado, elas já não são mais parceiras dos meios de hospedagem tradicionais que se concentram no Bairro de Ponta Negra, fato que diminuiu a atuação e presença das travestis em torno do turismo nos últimos 5 anos.

\section{CONSIDERAÇÕES FINAIS}

O turismo, indubitavelmente, é uma atividade que move diversos setores da economia local e mundial, com destaque aqui para o mercado do sexo, que naturalmente se fortalece nos destinos turísticos do mundo todo. Esse mercado é potencializado por algumas condições que são próprias do turismo, seja o isolamento do grupo social de origem do turista (que lhe impõe as regras de comportamento e os padrões morais), seja pelo volume de pessoas que circulam esporadicamente na área funcional turística, seja pelo encontro de diversas culturas em um mesmo espaço, que ocasiona uma maior tolerância ao diferente, seja pela condição de lazer e relaxamento que implica o turismo, mas, também, pela busca por sexo (atividade natural do ser humano) como lazer e entretenimento.

Essa pesquisa resume o vasto universo da prostituição das travestis no destino turístico Natal, no Rio Grande do Norte, Brasil, demonstrando quanto ainda há a se pesquisar e quão difícil é se inserir neste universo que, por convenções sociais tradicionais, permanece em segredo. O perfil de turistas estrangeiros, de meia idade e brancos, perdura no mundo das travestis como uma importante fonte de renda, mas também de exploração e risco. Essas garotas retratam, ainda, a difícil vida de pessoas que foram negadas por suas famílias e que sofrem diariamente os preconceitos de uma sociedade heteronormativa que exclui tudo que não lhe pareça natural da condição biológica de homem e mulher.

Além disso, o sexo continua sendo um tema que causa divergências entre pesquisadores, que normalmente não entendem o fenômeno da prostituição como parte natural e inevitável do desenvolvimento dos destinos turísticos, especialmente nos grandes centros urbanos. É pela moral social que se reduz o mercado do sexo à marginalidade no 
Brasil, potencializando riscos e estigmas que ferem a condição humana daqueles que sobrevivem desse cenário e que, de uma forma mais velada, também colaboram com a produção e a hospitalidade no destino turístico Natal.

\section{REFERÊNCIAS}

Almeida, M. V. de. (2009). A chave do armário: homossexualidade, casamento e família. Lisboa, ICS.

Assunção, L. W. (2009). Turismo sexual no brasil: causas e efeitos ao turismo brasileiro. Trabalho de Conclusão de Curso de Turismo, Centro Universitário La Salle - Unilasalle, Canoas, RS, Brasil.

Assunção, L. W. \& Babinski, L. R. (2010). Turismo sexual no Brasil: Causas e efeitos ao turismo brasileiro. Anais do I Econtro Semitur Jr. Seminário de Pesquisa em Turismo do Mercosul, Caxias do Sul, RS, Brasil,

Bauman, Z. (2008). Vida para consumo: a transformação das pessoas em mercadorias. Rio de Janeiro, Jorge Zahar.

Bem, A. S. (2005). A dialética do turismo sexual. Campinas, Papirus.

Bignami, R. (2002). A imagem do Brasil no turismo: construção, desafios e vantagem competitiva. São Paulo, Aleph.

Buarque, C. (1973). Não Existe Pecado ao Sul do Equador. Rio de Janeiro, RJ: 1973.

Carvalho, P. (2006). Estrutura para o Turismo Sexual. Jornal da Globo. Recuperado em 28, junho, 2017, de http://jg.globo.com/JGlobo/0,19125,VTJ0-2742-20060308- 154489,00.html.

Cavalcante, A. C. (2011). As Iracemas e os príncipes além-mar: políticas públicas e a exploração do turismo sexual. Dissertação Mestrado em Administração de Empresas, Universidade de Fortaleza, Fortaleza, CE, Brasil.

Dutra, J. L. A. (2008). O estado-da-arte: situação, ações, distorções e omissões na relação entre turismo e combate à exploração sexual comercial de crianças e adolescentes na cidade do Rio de Janeiro. In Tenório, F. G. \& Barbosa, L. G. M. O setor turístico versus a exploração sexual na infância e na adolescência. Rio de Janeiro: Fundação Getúlio Vargas.

Federação do Comércio - Fecomércio RN. (2017). Turista que visita Natal na alta estação vem do Sudeste e permanece, em média, 10 dias na cidade. Recuperado em 07, maio, 2018, de http://fecomerciorn.com.br/noticias/turista-que-visita-natal-na-alta-estacao-vem-dosudeste-e-permanece-em-media-10-dias-na-cidade/.

França, G. V. (2012). Prostituição: um enfoque político social. Femina, 22(2), 145-148.

G1 Brasil. (2011). Polícia apura favorecimento à prostituição em Natal e no Recife. Recuperado em 07, julho, 2018, de http://g1.globo.com/brasil/noticia/2011/03/policia-apurafavorecimento-prostituicao-em-natal-e-no-recife.html. 
Gabrielli, C. P. (2006). Das "vergonhas" descritas por caminha, ao turismo sexual: O uso de imagens femininas atreladas ao desenvolvimento turístico do Brasil. Dissertação Mestrado em Cultura e Turismo, Universidade Estadual de Santa Cruz, Ilhéus, BA, Brasil.

Gil, A. C. (2002). Como elaborar projetos de pesquisa. São Paulo, Atlas.

Jornal O Globo. (2006). Estrutura para o turismo sexual. Recuperado em 07, julho, 2018, de http://g1.globo.com/jornaldaglobo/0,,MUL890622-16021,00-

ESTRUTURA+PARA+O+TURISMO+SEXUAL.html

Lanzarini, R. (2016). Zonas livres: entre trabalho, viagens e sexo. Ituiutaba/MG, Barlavento.

Leite, M. J. S. (2007). Turismo sexual: a exploração das mulheres na dinâmica do turismo sexual. Chame: Centro Humanitário de Apoio à Mulher, Salvador/BA.

Mott, L. \& Michels, E. (2017). Pessoas LGBT mortas no brasil: Relatório 2017. Recuperado em 05, junho, 2018, de https://homofobiamata.files.wordpress.com/2017/12/relatorio2081.pdf.

Olivieri, A. C. \& Villa, M. A. (1999). Carta do Achamento do Brasil. São Paulo, Callis.

Otani, N. \& Fialho, F. A. P. (2011). TCC: métodos e técnicas. Florianópolis, Visual Books.

Parlamento Europeu (2016). Parlamento Europeu diz que 21 milhões de pessoas são vítimas de tráfico. Agência Brasil. Recuperado de

http://agenciabrasil.ebc.com.br/internacional/noticia/2016-10/parlamento-europeu-diz-que-21milhoes-de-pessoas-sao-vitimas-de

Piscitelli, A. (2005). Turismo sexual envolve amor, sonho, casamento e ascensão. Folha de São Paulo. Recuperado em 30, janeiro, 2019, de https://www1.folha.uol.com.br/fsp/brasil/fc3101200514.htm.

Russo, G. H. A. (2006). Rodando a bolsinha: dinheiro e relações de prostituição. Tese Doutorado em Ciências Sociais, Universidade Federal do Rio Grande do Norte, Natal, RN, Brasil.

Tribuna do Norte. (2011). Prostituição e tráfico de drogas continuam "liberados" na noite de Ponta Negra. Recuperado em 07, julho, 2018, de

http://www.tribunadonorte.com.br/noticia/prostituicao-e-trafico-de-drogas-continuamliberados-na-noite-de-ponta-negra/175608.

Trigo, L. G. G. (2007). Análises regionais e globais do turismo brasileiro. São Paulo: Roca.

LANZARINI, R., GURGEL, K. V. \& SILVA, M. J. V. (2019). Destino de Prazer: Turismo e prostituição na ótica de travestis em Natal/RN, Brasil. Revista de Turismo Contemporâneo, 7(2), 202-219. https://doi.org/10.21680/2357-8211.2019v7n2ID16819 